\title{
Novel Differential Refractometry Study of the Enzymatic Degradation Kinetics of Poly(ethylene oxide)-b-poly( $\epsilon$-caprolactone) Particles Dispersed in Water
}

\author{
HiuFung Lam, ${ }^{\dagger, \ddagger}$ Xiangjun Gong, ${ }^{\S}$ and Chi Wu, $\mathbf{W u}^{*, \dagger, \hbar}$ \\ The Hefei National Laboratory for Physical Sciences at Microscale and the Department of Chemical Physics, \\ The University of Science and Technology of China, Hefei, Anhui, 230026 China, The Department of \\ Chemistry, The Chinese University of Hong Kong, Shatin, N.T., Hong Kong, China, and \\ The Department of Physics, The Chinese University of Hong Kong, Shatin, N.T., Hong Kong, China
}

Received: October 3, 2006; In Final Form: November 22, 2006

\begin{abstract}
A poly(ethylene oxide)- $b$-poly( $\epsilon$-caprolactone) (PEO- $b$-PCL) diblock copolymer was micronized into small micelle-like particles $(\sim 80 \mathrm{~nm})$ via dialysis-induced microphase inversion. The enzymatic biodegradation of the PCL portion of these particles in water was in situ investigated inside a recently developed novel differential refractometer. Using this refractometry method, we were able to monitor the real-time biodegradation via the refractive index change $(\Delta n)$ of the dispersion because $\Delta n$ is directly proportional to the particle mass concentration. We found that the degradation rate is proportional to either the polymer or enzyme concentration. Our results directly support previous speculation on the basis of the light-scattering data that the biodegradation follows the first-order kinetics for a given enzyme concentration. This study not only leads to a better understanding of the enzymatic biodegradation of PCL, but also demonstrates a novel, rapid, noninvasive, and convenient way to test the degradability of polymers.
\end{abstract}

\section{Introduction}

Many methods have been developed for the study of biodegradation of polymeric materials, such as enzymatic degradation ${ }^{1,2}$ and microbial degradation ${ }^{3-5}$ in different environments, (e.g., burial in soil and immersion in soil or natural water). The polymer biodegradation has been examined in terms of a wide range of properties, including macroscopic weight loss,${ }^{6}$ oxygen consumption and carbon dioxide emission, ${ }^{7}$ scattering intensity, ${ }^{8}$ titrimetry, ${ }^{9}$ tensile strength, ${ }^{10}$ surface morphology, ${ }^{11,12}$ crystallinity, ${ }^{13}$ viscosity ${ }^{14}$ and molar mass, ${ }^{15}$ to name but a few. On the other hand, the biodegradation of polymers in different forms, such as thin films, pastes, small particles, fibers, and sponges, has also been tested for various purposes, including tissue and bone bioengineering ${ }^{16-18}$ and drug delivery. ${ }^{19-21}$

It is helpful to note that most of the current analytical methods used for the degradation study are not based on an in situ and direct measurement of polymer concentration change. Namely, the degradation and characterization of remaining polymer chains are separately performed. For example, Paige et al. ${ }^{22}$ and Rossini et al., ${ }^{23}$ respectively, measured the real-time enzymatic biodegradation of collagen fibrils and polymeric thin films using atomic force microscopy in terms of their morphologic changes. $\mathrm{Wu}$ and his associates ${ }^{8,24-29}$ developed an in situ laser lightscattering (LLS) method to study the biodegradation by monitoring the scattering intensity change. However, it should be noted that it is not trivial to connect these changes to the polymer concentration change without some serious assumptions. Considering such a limitation, we have recently developed

* Address correspondence to this author at The Chinese University of Hong Kong.

$\dagger$ The University of Science and Technology of China.

$\doteqdot$ The Department of Chemistry, The Chinese University of Hong Kong.

$\S$ The Department of Physics, The Chinese University of Hong Kong. a differential refractometry method for an in situ and direct measurement of polymer concentration change so that the degradation kinetics can be accurately and precisely measured without any pre-assumption.

In the current study, we chose a poly(ethylene oxide)- $b$-poly$(\epsilon$-caprolactone) (PEO- $b$-PCL) diblock copolymer to demonstrate how its enzymatic biodegradation can be investigated by the refractometry method. The reason of choosing such a copolymer is because we know how to micronize it into small particles stably dispersed in water and also because we have some doubts about previous LLS studies on a similar polymer system. ${ }^{24-29}$ It has been shown that in comparison with a thin film $(\sim 100 \mu \mathrm{m})$, the micronization of biodegradable polymers into small submicrometer particles could speed up the degradation by $10^{4}$ times or more. ${ }^{8}$ In other words, the micronization can greatly shorten the measurement time and provide a quick method to evaluate the degradability of a given polymer, which is vitally important for industrial research and development, where time is money.

The micronization of PEO- $b$-PCL is relatively easy because of its amphiphilic nature: it can self-assemble in aqueous solution without any surfactant to form small micelle-like particles with a swollen hydrophilic PEO shell and a collapsed hydrophobic PCL core. It should be noted that in some biomedical applications, the addition of surfactant in the micronization could be harmful. This is why this kind of PEO$b$-PCL copolymers have been widely tested as potential drug carriers. ${ }^{30,31}$ In the current study, besides the illustration of the principle of our differential refractometry method, we have focused on the polymer and enzyme concentration dependence of the biodegradation kinetics as well as the mechanism.

\section{Experimental Section}

Materials and Sample Preparation. A poly(ethylene oxide)$b$-poly( $\epsilon$-caprolactone) (PEO- $b$-PCL) diblock copolymer $\left(M_{\mathrm{w}}\right.$ 

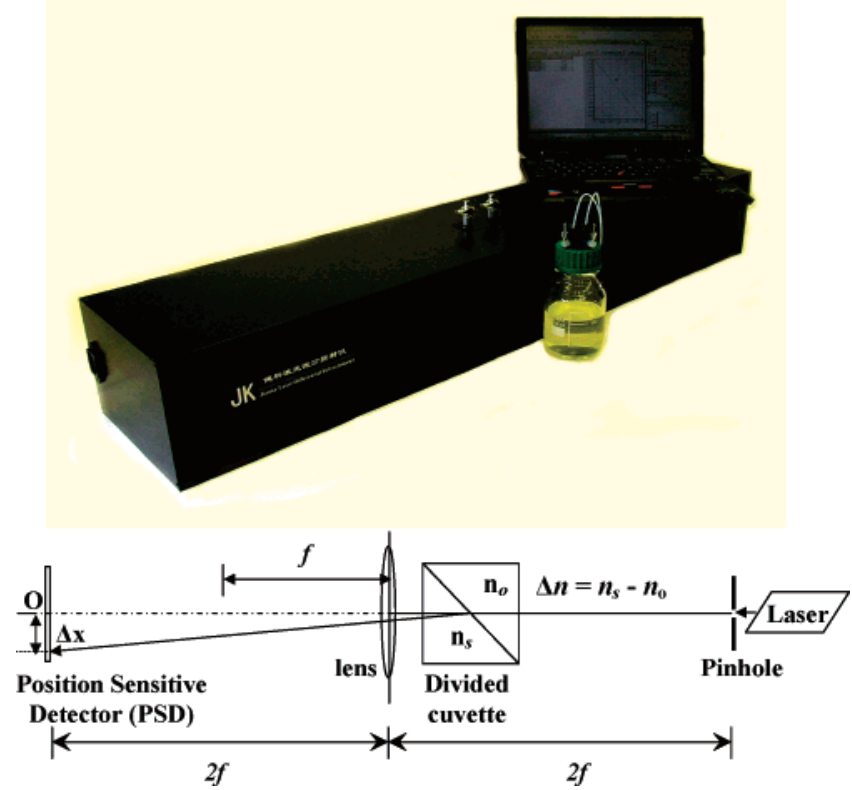

Figure 1. Novel differential refractometer (Jianke Instrument, Ltd., China) used in this study and sketch of its optical path. One divided cell contains a refrence solvent or solution with a refractive index of $n_{0}$ and the other contains a sample solution with a slightly different refractive index of $n_{\mathrm{s}}$.

$=3.1 \times 10^{4} \mathrm{~g} / \mathrm{mol}$ and $W_{\mathrm{PEO}}: W_{\mathrm{PCL}}=1: 2$ ) was synthesized by ring-opening polymerization of a prescribed amount of $\epsilon$-caprolactone (CL) initiated by a macroinitiator poly(ethylene oxide) $\left(M_{\mathrm{w}}=1.0 \times 10^{4} \mathrm{~g} / \mathrm{mol}\right)$ at $130{ }^{\circ} \mathrm{C}$ in the presence of stannous octoate as a catalyst. The synthesis detail can be found elsewhere. ${ }^{32}$ Small micelle-like PEO- $b$-PCL particles were prepared by a dialysis method, ${ }^{33}$ which is outlined as follows.

Copolymer solution $(5 \mathrm{~mL})$ in $\operatorname{THF}\left(5.00 \times 10^{-3} \mathrm{~g} / \mathrm{mL}\right)$ was transferred into a preswollen semipermeable membrane (Spectra/ For, USA) and dialyzed against an excess amount of deionized water $(500 \mathrm{~mL})$. The dialysate was gently stirred. Water outside of the tube was exchanged every $8 \mathrm{~h}$ for 2 days. As water and THF continuously diffuse in and out, the solvent mixture inside the dialysis tube gradually becomes a poor solvent for the PCL block. As expected, the intrachain contraction and interchain association of insoluble PCL blocks would result in small coreshell micelle-like particles with a collapsed hydrophobic PCL core and a swollen hydrophilic PEO shell. The final polymer concentration of such a stock dispersion was $3.07 \times 10^{-3} \mathrm{~g} / \mathrm{mL}$. In this study, lipase PS from psedomonas cepacia (Amano Pharmaceutical, Japan) was used as a biocatalyst to degrade the PCL core. The crude lipase PS was purified by dissolving it in a $0.1 \mathrm{M}$ phosphate buffer solution. The solution was filtered by a $0.45-\mu \mathrm{m}$ Millipore filter. The filtrate was freeze-dried and stored at $-18{ }^{\circ} \mathrm{C}$ prior to use. The purified lipase PS is a lightyellow powder and readily soluble in water.

Differential Refractometer. A novel laser differential refractometer (Jianke Instrument Ltd., China) based on the Snell's law of refraction and our novel $2 \mathrm{f}-2 \mathrm{f}$ optical design was recently developed, as shown in Figure 1. In this differential refractometer, the $2 \mathrm{f}-2 \mathrm{f}$ optical design is used to overcome the unavoidable drifting problem of the laser beam. Namely, the pinhole $(200 \mu \mathrm{m})$ is illuminated by a laser beam and focused on the position sensitive detector. Optically, it is equivalent to put the pinhole directly on the detector. Therefore, the beam drifting will not affect the position of the pinhole image on the detector. A small difference in polymer concentrations or compositions or any other properties related to refractive index between the two divided cells will deflect the pinhole image. In the current design, the precision of the measured refractive index change is close to $\sim 10^{-6} \mathrm{RI}$ unit, corresponding to a polymer concentration change as small as $\sim 10^{-5} \mathrm{~g} / \mathrm{mL}$. The equipped analog-to-digital data acquisition system allows a realtime measurement of refractive index change. An internal thermoelectric module is used as a built-in thermostat to regulate the temperatures of the two divided cells in the range 15-50 ${ }^{\circ} \mathrm{C}$ with a long-term stability of $\pm 0.1^{\circ} \mathrm{C}$. Note that no external heating bath is required for such a differential refractometer. The detailed principle of such a refractometer can be found elsewhere. ${ }^{34}$ The measured voltage change from the position sensitive detector is proportional to the shifting of the pinhole image, or in other words, to the refractive index difference $(\Delta n)$ between the sample ( $\left.n_{\text {sample }}\right)$ and the reference $\left(n_{\text {reference }}\right)$ solutions/dispersions, respectively, in the two cells, i.e.,

$$
\Delta n=n_{\text {sample }}-n_{\text {reference }}=c \Delta V
$$

where $c$ is an instrument constant. In the current design, $c=$ $(8.94 \pm 0.01) \times 10^{-4} \mathrm{~V}^{-1}$. All the biodegradation studies reported hereafter were done at $37.0 \pm 0.1{ }^{\circ} \mathrm{C}$ if not specified otherwise. Into both the reference and sample cells, the same copolymer dispersion was added except that the sample cell contained a desired amount of enzyme. Each time, only $\sim 10$ $\mu \mathrm{L}$ dispersion was injected into each divided cell. The temperature equilibrium inside the cell can be reached within $\sim 1$ min. The initial position of the pinhole image on the detector after the temperature equilibrium was used as a starting point. In this way, we can experimentally take care of the enzyme induced shifting of the laser beam.

Laser Light Scattering. A commercial LLS spectrometer (ALV/SP-125) equipped with an multi- $\tau$ digital correlator (ALV5000/E) and a 22-mW HeNe laser (JDS-Uniphase 1145P) was used. The incident beam was vertically polarized with respect to the scattering plane. The details of LLS instrumentation and principles can be found elsewhere. ${ }^{35}$ In static LLS, the scattering angle $(\theta)$ and polymer concentration $(C, \mathrm{~g} / \mathrm{mL})$ dependence of the absolute time-averaged scattered light intensity, known as the excess Rayleigh radio $\left(R_{\mathrm{vv}}(q)\right)$, of a sufficiently dilute polymer solution can lead to the weight-averaged molar mass $\left(M_{\mathrm{w}}\right)$, the second virial coefficient $\left(A_{2}\right)$, and the z-average mean square radius of gyration $\left\langle R_{\mathrm{g}}{ }^{2}\right\rangle$ as

$$
\frac{K C}{R_{\mathrm{vv}}(q)} \approx \frac{1}{M_{\mathrm{w}}}\left(1+\frac{1}{3}\left\langle R_{\mathrm{g}}{ }^{2}\right\rangle q^{2}\right)+2 A_{2} C
$$

where $K\left[=4 \pi(\mathrm{d} n / \mathrm{d} C)^{2} /\left(N_{\mathrm{A}} \lambda^{4}\right)\right]$ is a constant for a given polymer solution/dispersion and $q[=(4 \pi / \lambda) \sin (\theta / 2)]$ is the scattering vector, with $\mathrm{d} n / \mathrm{d} C, N_{\mathrm{A}}$, and $\lambda_{\mathrm{o}}$ being the specific refractive index increment, the Avogadro number, and the light wavelength in vacuum, respectively.

In dynamic LLS, the Laplace inversion analysis of a measured intensity-intensity time correlation function $\left(G^{(2)}(q, t)\right)$ can result in a characteristic line-width distribution $(G(\Gamma))$. For a narrowly distributed sample, the cumulant analysis of $G^{(2)}(q, t)$ can lead to an accurate average characteristic line-width $\langle\Gamma\rangle$. For a pure diffusive relaxation, $\Gamma$ is related to the translational diffusion coefficient $\langle D\rangle$ by $D=\left(\Gamma / q^{2}\right)_{q \rightarrow 0, c \rightarrow 0}$ or the hydrodynamic radius $\left\langle R_{\mathrm{h}}\right\rangle$ by $R_{\mathrm{h}}=k_{\mathrm{B}} T /(6 \pi \eta D)$, where $k_{\mathrm{B}}, T$, and $\eta$ are the Boltzmann constant, the absolute temperature, and the solvent viscosity, respectively. 


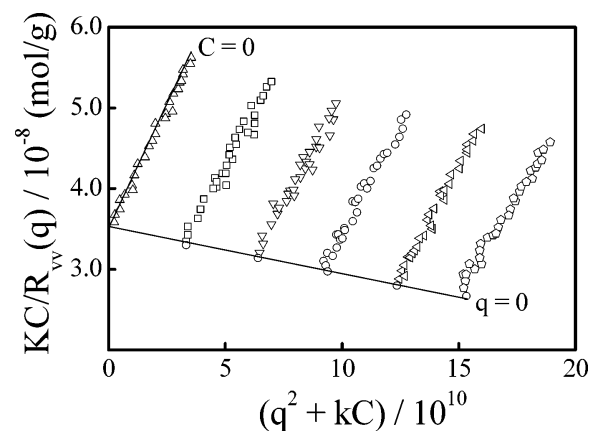

Figure 2. Zimm plot of PCL- $b$-PEO micelle-like particles dispersed in water. The polymer concentration ranges from $1.15 \times 10^{-5}$ to 5.03 $\times 10^{-5} \mathrm{~g} / \mathrm{mL}$.

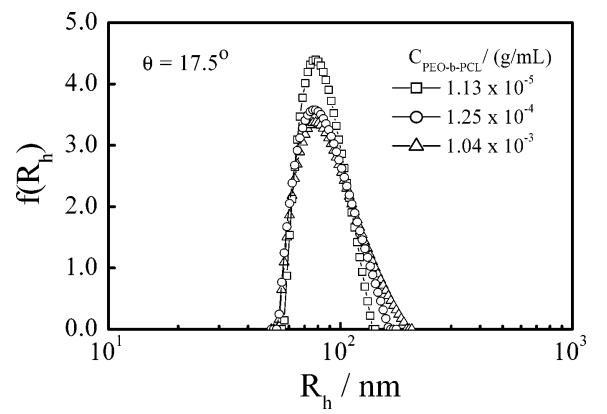

Figure 3. Hydrodynamic radius distributions $\left(f\left(R_{\mathrm{h}}\right)\right)$ of PCL- $b$-PEO micelle-like particles dispersed in water.

TABLE 1: Laser Light-Scattering Characterization of Small Micelle-like PEO- $b$-PCL Spherical Particles Dispersed in Water at $37{ }^{\circ} \mathrm{C}$, Where $W_{\text {PCL }}: W_{\text {PEO }}=2: 1$

\begin{tabular}{cccccccc}
\hline $\begin{array}{c}M_{\mathrm{w}, \text { chain }}, \\
\mathrm{g} / \mathrm{mol}\end{array}$ & $\begin{array}{c}\mathrm{M}_{\mathrm{w}, \text { article }}, \\
\mathrm{g} / \mathrm{mol}\end{array}$ & $\begin{array}{c}A_{2}, \\
\mathrm{agg}\end{array}$ & $\begin{array}{c}\left\langle R_{\mathrm{g}}\right\rangle, \\
\mathrm{mol} \cdot \mathrm{m}^{3} / \mathrm{g}^{2}\end{array}$ & $\begin{array}{c}\left\langle R_{\mathrm{h}}\right\rangle, \\
\mathrm{nm}\end{array}$ & $\mathrm{nm}$ & $\mu /\langle\Gamma\rangle^{2}$ & $\begin{array}{c}\langle\rho\rangle, \\
\mathrm{g} / \mathrm{cm}^{3}\end{array}$ \\
\hline $3.1 \times 10^{4}$ & $2.9 \times 10^{7}$ & 920 & $-1.1 \times 10^{-4}$ & 73 & 78 & $\sim 0.1$ & 0.024
\end{tabular}

\section{Results and Discussion}

Figure 2 shows a typical Zimm plot from small micelle-like PCL- $b$-PEO particles dispersed in deionized water at $37^{\circ} \mathrm{C}$, in which the concentration and angular dependence of $R_{\mathrm{vv}}(q)$ are incorporated on a single grid. Equation 2 shows that the extrapolation of $\left[K C / R_{\mathrm{vv}}(q)\right]_{C \rightarrow 0, q \rightarrow 0}$ leads to the weight-averaged molar mass $\left(M_{\mathrm{w}}\right)$. The slopes of " $\left[K C / R_{\mathrm{vv}}(q)\right]_{C \rightarrow 0}$ versus $q^{2}$ " and " $\left[K C / R_{\mathrm{vv}}(q)\right]_{q \rightarrow 0}$ versus $C$ " result in the $z$-average mean-square gyration radius $\left\langle R_{\mathrm{g}}{ }^{2}\right\rangle$ and the second virvial coefficient $A_{2}$, respectively. The results are summarized in Table 1 . The negative value of $A_{2}$ indicates that overall water is a poor solvent for these particles even thought the PEO block is still soluble in water at $37^{\circ} \mathrm{C}$.

Figure 3 shows three normalized hydrodynamic radius distributions $f\left(R_{\mathrm{h}}\right)$ of small PEO- $b$-PCL particles dispersed in water with different copolymer concentrations at $37^{\circ} \mathrm{C}$, where $f\left(R_{\mathrm{h}}\right)$ is calculated from each corresponding measured $G^{(2)}(q, t)$ by using the Laplace inversion CONTIN program in the correlator. The results are also summarized in Table 1. The relative distribution width $\mu /\left\langle\Gamma^{2}\right\rangle$ of $G(\Gamma)$ is less than $\sim 0.1$, indicating that these particles are narrowly distributed in size. The effect of dilution on $\left\langle R_{\mathrm{h}}\right\rangle$ is no more than $3 \%$. In other words, the dilution of $\sim 100$ times does not disintegrate these stable particles, indicating that their critical micelle or aggregation concentration (CMC or CAC) is extremely low. It is helpful to note that it is this extremely low CMC or CAC that makes this kind of copolymers ideal for drug delivery.

A combination of static and dynamic LLS results shows that the ratio of the average radius of gyration to the average

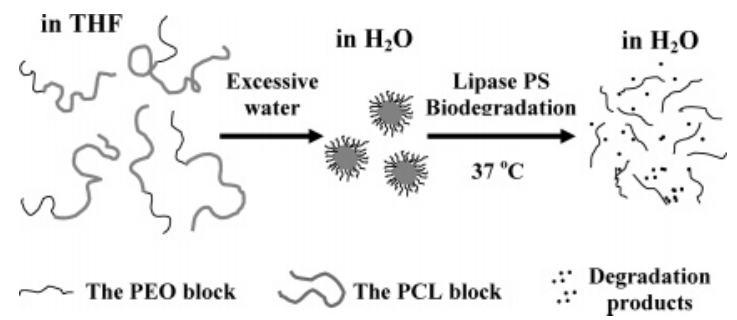

Figure 4. Schematic of micronization of diblock PEO- $b$-PCL copolymer chains into small micelle-like core-shell particles via dialysisinduced microphase inversion and their corresponding biodegradation in water.

hydrodynamic radius $\left\langle R_{\mathrm{g}}\right\rangle /\left\langle R_{\mathrm{h}}\right\rangle$ is 0.9 , slightly larger than 0.774 predicted for a uniform and nondraining sphere. This higher value could be attributed to a swollen partially draining PEO shell or reflect a less compact PCL core. The ratio of $M_{\mathrm{w}, \text { aggregation }} / M_{\mathrm{w}, \text { chain }}$ leads to an average aggregation number $\left(N_{\mathrm{agg}} \approx 900\right)$. The average particle density $(\rho)$, defined as $M_{\mathrm{w}} /$ $\left[N_{A}(4 / 3) \pi\left\langle R_{\mathrm{h}}\right\rangle^{3}\right]$, is much lower than that $\left(\sim 1 \mathrm{~g} / \mathrm{cm}^{3}\right)$ of bulk polymers, revealing that the hydrodynamic volume of each particle contains a lot of water and the chains are loosely aggregated together, as schematically shown in Figure 4.

As mentioned before, into the sample and reference cells, we fill in the same dispersion. Note that unlike in LLS, here a completely dust-free environment is not required, making the experiment much easier. The only difference was that a small amount of enzyme was added into the sample cell. For an attentive reader, the addition of this small amount of enzyme must shift the image of the pinhole on the detector, which is true. Therefore, we used this new position as our starting point in the in situ measurement of $\Delta n$ : namely, we experimentally subtracted this additional enzyme influence on the beam refraction. It is helpful to note that the refractive index $(n)$ of a dilute solution or dispersion is additive for each component inside, ${ }^{36,37}$ i.e.

$$
n_{0}=n_{\mathrm{w}}+\left(\frac{\mathrm{d} n}{\mathrm{~d} C}\right)_{\mathrm{PEO}} C_{\mathrm{PEO}, 0}+\left(\frac{\mathrm{d} n}{\mathrm{~d} C}\right)_{\mathrm{PCL}} C_{\mathrm{PCL}, 0} \quad(\text { at } t=0)
$$

and

$n_{t}=n_{\mathrm{w}}+\left(\frac{\mathrm{d} n}{\mathrm{~d} C}\right)_{\mathrm{PEO}} C_{\mathrm{PEO}, 0}+\left(\frac{\mathrm{d} n}{\mathrm{~d} C}\right)_{\mathrm{PCL}} C_{\mathrm{PCL}, t}+\left(\frac{\mathrm{d} n}{\mathrm{~d} C}\right)_{\mathrm{dp}} C_{\mathrm{dp}, t}$

(at $t=t$ )

where $n_{\mathrm{w}}$ is the refractive index of water, $C_{\mathrm{PEO}}, C_{\mathrm{PCL}}$, and $C_{\mathrm{dp}}$ are the weight concentrations $(\mathrm{g} / \mathrm{mL})$ of PEO and PCL and degradation products (low molecular weight acids), respectively, and $\mathrm{d} n / \mathrm{d} C$ is the refractive index increment, a constant for a given polymer solution or dispersion, depending only on the chemical nature but not on the concentration. $C_{\mathrm{PCL}, 0}=C_{\mathrm{PCL}, t}$ $+C_{\mathrm{dp}, t}$. Using the initial dispersion in the reference cell as a reference and noting that $C_{\mathrm{PEO} O}$ is a constant during the biodegradation because PEO is not biodegradable in this case, we can define

$$
\Delta n_{t}=n_{0}-n_{t}=\left[\left(\frac{\mathrm{d} n}{\mathrm{~d} C}\right)_{\mathrm{PCL}}-\left(\frac{\mathrm{d} n}{\mathrm{~d} C}\right)_{\mathrm{dp}}\right]\left(C_{\mathrm{PCL}, 0}-C_{\mathrm{PCL}, t}\right)
$$

It is clear that $\Delta n_{t}$ is only proportional to the change of PCL concentration in the dispersion.

Figure 5 shows the biodegradation-time dependence of the refractive index changes $\Delta n_{t}$ at $37{ }^{\circ} \mathrm{C}$ with different copolymer/ enzyme ratios. Note that each PEO- $b$-PCL copolymer chain contains $2 / 3$ PCL in mass, i.e., $C_{\mathrm{PCL}, 0}=(2 / 3) C_{\mathrm{PEO}-b-\mathrm{PCL}, 0 \text {. For }}$ 


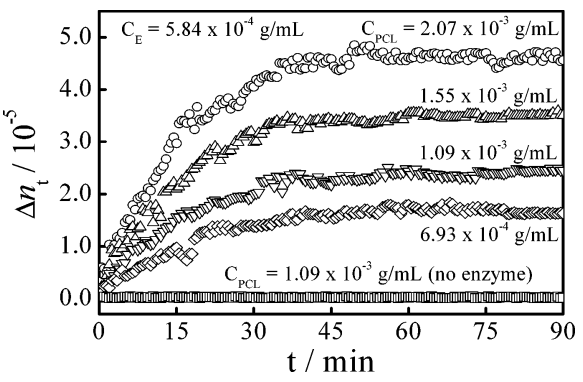

Figure 5. Biodegradation-time dependence of refractive index change $\left(\Delta n_{\mathrm{t}}\right)$ of PEO-b-PCL particles dispersion at $37^{\circ} \mathrm{C}$, where the enzyme concentration was kept a constant.

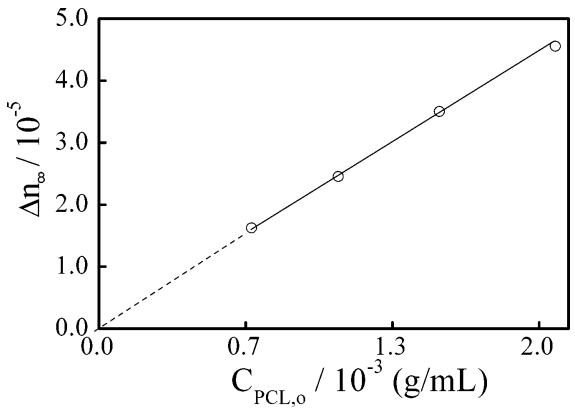

Figure 6. Initial copolymer concentration dependence of final and maximum refractive index change $\left(\Delta n_{8}\right.$, as shown in Figure 5) after a long degradation time. Note that $C_{\mathrm{PCL}, 0}$ is $2 / 3$ of the initial PEO- $b$-PCL copolymer concentration $\left(C_{\mathrm{PEO}-b-\mathrm{PCL}}\right)$ since $W_{\mathrm{PCL}, 0}: W_{\mathrm{PEO}, 0}$ is $2: 1$.

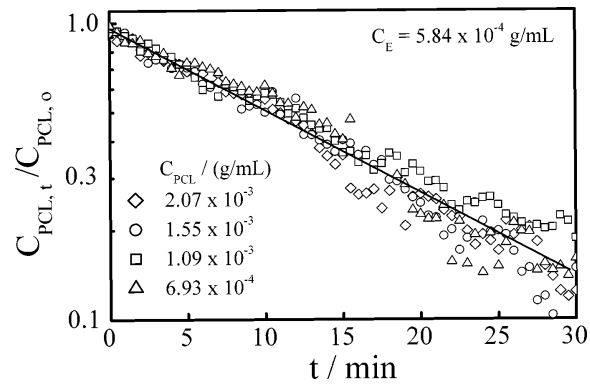

Figure 7. Semilogarithmic plot of " $\left(C_{\mathrm{PCL}, t} / C_{\mathrm{PCL}, \mathrm{p}}\right)$ versus $t$ " for PEO$b$-PCL micelle-like particle dispersions with different initial copolymer concentrations.

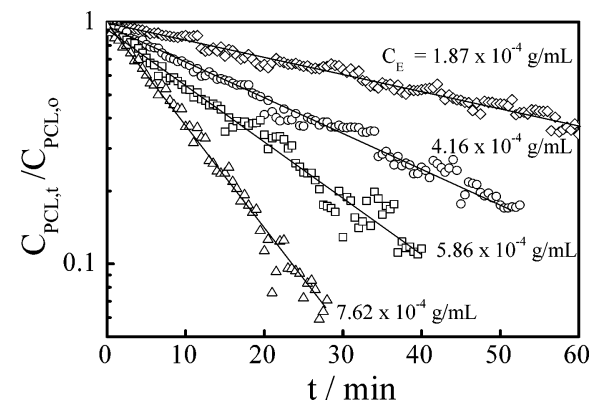

Figure 8. Plot of " $\log \left(C_{\mathrm{PCL}, t} / C_{\mathrm{PCL}, 0}\right)$ versus $t$ " for PEO- $b$-PCL micellelike particle dispersions with different enzyme concentrations.

a given enzyme concentration $\left(5.84 \times 10^{-4} \mathrm{~g} / \mathrm{mL}\right)$, the biodegradation stops after ca. 40-60 min. Assuming that all the PCL blocks are completely biodegraded at $t \rightarrow \infty$, we have, on the basis of eq 5 ,

$$
\Delta n_{\infty}=\left[\left(\frac{\mathrm{d} n}{\mathrm{~d} C}\right)_{\mathrm{PCL}}-\left(\frac{\mathrm{d} n}{\mathrm{~d} C}\right)_{\mathrm{dp}}\right] C_{\mathrm{PCL}, 0}
$$

Note that it is impossible to directly measure $(\mathrm{d} n / \mathrm{d} C)_{\mathrm{PCL}}$ because PCL is insoluble in water. On the other hand, we also do not

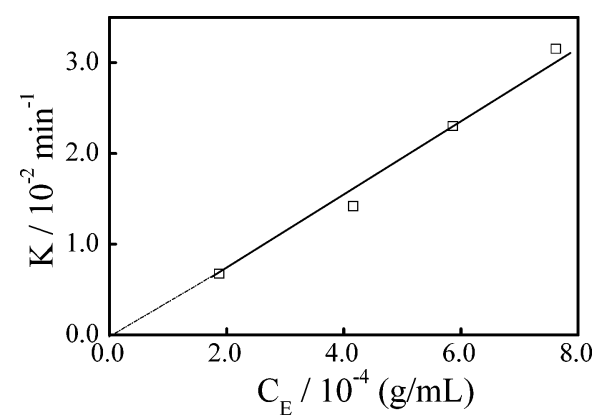

Figure 9. Enzyme concentration dependence of apparent biodegradation rate constant $(K)$ where $K$ was obtained from the fitting of "log$\left(C_{\mathrm{PCL}, t} / C_{\mathrm{PCL}, 0}\right)=K t^{\prime \prime}$ over the results in Figure 8.

know $(\mathrm{d} n / \mathrm{d} C)_{\mathrm{dp}}$. However, on the basis of eq 6 , a plot of $\Delta n_{\infty}$ versus $C_{\mathrm{PCL}, 0}$ should be a straight line and the slope should lead to the difference between $(\mathrm{d} n / \mathrm{d} C)_{\mathrm{PCL}}$ and $(\mathrm{d} n / \mathrm{d} C)_{\mathrm{dp}}$.

Figure 6 shows such a plot at $37{ }^{\circ} \mathrm{C}$. To ensure a complete biodegradation, each $\Delta n_{\infty}$ was measured after $\sim 10 \mathrm{~h}$ of biodegradation, but it did not change much after 40-60 min. Indeed, Figure 6 shows that $\Delta n_{\infty}$ is indeed proportional to $C_{\mathrm{PCL}, 0}$ and the extrapolation passes the origin, indicating that $C_{\mathrm{PCL}, \infty} \rightarrow$ 0 . In other words, the biodegradation is really completed after $\sim 1 \mathrm{~h}$. The slope of the fitting line is $0.0219 \pm 0.0005 \mathrm{~mL} / \mathrm{g}$, indicating that $(\mathrm{d} n / \mathrm{d} C)_{\mathrm{dp}}$ is smaller than $(\mathrm{d} n / \mathrm{d} C)_{\mathrm{PCL}}$, but the difference is fairly small, which is expected because the degradation products are small water-soluble acids. The hydration normally lowers the refractive index of a substance in water. Furthermore, we have, on the basis of eqs 5 and 6 ,

$$
\frac{C_{\mathrm{PCL}, t}}{C_{\mathrm{PCL}, 0}}=\frac{\Delta n_{\infty}-\Delta n_{t}}{\Delta n_{\infty}}
$$

where $\Delta n_{\infty}$ is a constant for a given initial copolymer concentration.

Figure 7 shows the biodegradation-time dependence of $C_{\mathrm{PCL}, t}$ $C_{\mathrm{PCL}, 0}$ of four PEO- $b$-PCL dispersions with different initial copolymer concentrations. It is clear that for a given enzyme concentration, the data points in Figure 7 collapse into a single line and can be represented by $\log \left(C_{t} / C_{0}\right)=K t$ with $K=0.029$ $\pm 0.001 \mathrm{~min}^{-1}$. It reveals that the biodegradation indeed follows the first-order kinetics. In principle, an enzymatic reaction involves both enzyme and substrate molecules. The textbook kinetic theory tells us that the biodegradation rate $(\mathrm{d} C / \mathrm{d} t)$ is proportional to both the enzyme concentration $\left(C_{\mathrm{E}}\right)$ and the substrate concentration $(C)$, i.e.,

$$
-\frac{\mathrm{d} C_{t}}{\mathrm{~d} t}=k C_{\mathrm{E}} C_{t}
$$

where the subscript " $t$ " denotes at time $t$ and $k$ is the biodegradation rate constant. As a catalyst, $C_{\mathrm{E}}$ is a constant during the degradation by its definition. Therefore, we have,

$$
\frac{C_{t}}{C_{0}}=e^{-k C_{\mathrm{E}} t} \quad \text { or } \quad \ln \frac{C_{t}}{C_{0}}=-k C_{\mathrm{E}} t
$$

On the basis of Figure $7, K=k C_{\mathrm{E}} / \log 10$ or $k=K \log 10 / C_{\mathrm{E}}$ $=49 \pm 3 \mathrm{~mL} /(\mathrm{g} \mathrm{min})$. It should be stated that we also plotted " $\left(\mathrm{C}_{\mathrm{PCL}, t} / \mathrm{C}_{\mathrm{PCL}, 0}\right)$ versus $t$ " as well as " $\left(\mathrm{C}_{\mathrm{PCL}, 0} / \mathrm{C}_{\mathrm{PCL}, t}\right)$ versus $t$ " to check whether the biodegradation could be better represented by the zeroth- or the second-order kinetics. Our fittings (not shown) reveal that eq 9 represents the best fitting. 
Figure 8 shows the biodegradation-time dependence of $C_{\mathrm{PCL}, t} /$ $C_{\mathrm{PCL}, 0}$ of four PEO- $b$-PCL dispersions with different enzyme concentrations for a given copolymer concentration. As expected, the biodegradation becomes slower as the enzyme concentration decreases. The slope of each line leads to a value of $K$. On the basis of eq 9 , the plot of " $K$ versus $C_{\mathrm{E}}$ " should be a straight line passing the origin, as shown in Figure 9. Here, the slope of the fitting line leads to the biodegradation rate constant $(k=45 \pm 4 \mathrm{~mL} /(\mathrm{g} \mathrm{min}))$. In comparison, the two values of $k$ obtained respectively from Figures 7 and 9 are fairly close if we consider all experimental uncertainties. Note that the noise could come from a possible slow evaporation of solvent from the two cells after a long-time measurement, which would shift the baseline.

\section{Conclusion}

The enzymatic biodegradation of poly(ethylene oxide)- $b$-poly( $\epsilon$-caprolactone) (PEO- $b$-PCL) can be in situ studied inside a novel differential refractometer after its micronization into small particles dispersed in water. This refractometry method leads to a novel, rapid, noninvasive, and convenient way to evaluate whether a given polymer is degradable as well as its degradation kinetics. It has a definite advantage over other existing methods because it can directly measure the in situ change of polymer concentration as low as $10^{-3} \mathrm{~g} / \mathrm{mL}$ with $1 \%$ accuracy without any assumption due to the proportion of the refractive index change $(\Delta n)$ to polymer concentration change. Our current study of the biodegradation of PEO- $b$-PCL over a wide range of enzyme/copolymer ratios provides direct evidence that the biodegradation indeed follows the first-order kinetics with a reaction rate constant of $\sim 47 \pm 4 \mathrm{~mL} /(\mathrm{g}$ min). A comparison of our current refractometry and previous laser light-scattering results reveals that the biodegradation of small polymer particles in dispersions resembles an "all-or-none" chemical reaction of small molecules in solution: namely, there exist only two possibilities for the two colliding molecules-reaction or nonreaction. In other words, small particles in the biodegradation disappear in a one-by-one fashion, not slowly decreasing its size, which is very different from the degradation of bulk polymers either in the form of a thin film or a granule, which could be attributed to a large surface area of small submicro particles. Finally, it is worth noting that the current method (a combination of differential refractometry and micronization) is readily used to evaluate the degradation of other polymers under different experimental conditions, such as $\mathrm{pH}$, temperature, and microorganism.

Acknowledgment. The financial support of the Hong Kong Special Administration Region RGC Earmarked Grant (CUHK 4036/05P, A/C 2160269) and the National Nature Science Foundation of China Special Instruments Grant (20127403) is gratefully acknowledged.

\section{References and Notes}

(1) Cai, H.; Dave, V.; Gross, R. A.; McCarthy, S. P. J. Polym. Sci., Part B: Polym. Phys. 1996, 34, 2701.

(2) Nagata, M.; Machida, T.; Sakai, W.; Tsutsumi, N. J. Polym. Sci., Part A: Polym. Chem. 1999, 37, 2005.

(3) Tokiwa, Y.; Jarerat, A. Macromol. Symp. 2005, 224, 367.

(4) Rohindra, D.; Sharma, P.; Khurma, J. Macromol. Symp. 2005, 224 323.

(5) Otal, E.; Mantzavinos, D.; Delgado, M. V.; Hellenbrand, R.; Lebrato, J.; Metcalfe, I. S.; Livingston, A. G. J. Chem. Technol. Biotechnol. 1997 70, 2, 147-156.

(6) Sheth, M.; Kumar, R. A.; Davé, V.; Gross, R. A.; McCarthy, S. P. J. Appl. Polym. Sci. 1997, 66 (8), 1495.

(7) Sawada, H. J. Polym. Degrad. Stab. 1998, 59, 365.

(8) Wu, C.; Jim, T. F.; Gan, Z.; Zhao, Y.; Wang, S. Polymer 2000, $41,3593$.

(9) Scherer, T.; Fuller, R. C.; Lenz, R. W. J. Environ. Polym. Degrad. 1994, 2, 263.

(10) De Diego, M. A.; Coleman, N. J.; Hench, L. L. J. Biomed. Mater. Res. 2000, 53 (3), 199

(11) Li, G.; Cai, Q.; Bei, J.; Wang, S. Polym. Adv. Technol. 2002, 13 (9), 636

(12) Younes, H.; Cohn, D. J. Biomed. Mater. Res. 1987, 21 (11), 1301.

(13) Park, A.; Cima, L. G. J. Biomed. Mater. Res. 1996, 31 (1), 17.

(14) Ishigaki, T.; Sugano, W.; Nakanishi, A.; Tateda, M.; Ike, M.; Fujita, M. T. Chemosphere 2004, 54 (3), 225.

(15) Maniar, M. L.; Advant, S. J.; Kalonia, D. S.; Simonelli, A. P. Polym. Adv. Technol. 1992, 3 (6), 303

(16) Zhihua, G.; Qizhi, L.; Jie, Z.; Xiabin, J. J. Polym. Degrad. Stab. 1997, 56, 209.

(17) Zhang, X. C.; Jackson, J. K.; Wong, W.; Min, W. X.; Cruz, T.;

Hunter, W. L.; Burt, H. M. Int. J. Pharm. 1996, 137, 199.

(18) Mooney, D. J.; Baldwin, D. F.; Suh, N. P.; Vacanti, L. P.; Langer, R.; Biomaterials 1996, 17, 1417.

(19) Grandfiles, C.; Flandroy, P.; Jérôme, R. J. Controlled Release 1996 $38,109$.

(20) Conti, B.; Bucolo, C.; Giannavola, C.; Puglisi, G.; Giunchedi, P.; Conte, U. Eur. J. Pharm. Sci. 1997, 5, 287.

(21) Chen, D. R.; Bei, J. Z.; Wang, S. G. J. Polym. Degrad. Stab. 2000 $67,455$.

(22) Paige, M. F.; Lin, A. C.; Goh, M. C. Int. Biodeterior. Biodegrad. 2002, 50 (1), 1

(23) Rossini, C. J.; Arceo, J. F.; McCarney, E. R.; Dennis, D. E.; Flythe, M. D.; Baron, S. F.; Augustine, B. H. Macromol. Symp. 2001, 167, 139. (24) Wu, C.; Gan, Z. Polymer 1998, 39 (18), 4429.

(25) Gan, Z.; Fung, J. T.; Jing, X.; Wu, C.; Kulicke, W. M. Polymer 1990, 40 (8), 1961.

(26) Gan, Z.; Fung, J. T.; Yuao, Z.; Wang, S.; Wu, C. Macromolecules 1999, $32(3), 590$.

(27) Zhao, Y.; Hu, T.; Lv, Z.; Wang, S.; Wu, C. J. Polym. Sci., Part B: Polym. Phys. 1999, 37 (23), 3288.

(28) Fu, J.; Wu, C. J. Polym. Sci., Part B 2001, 39 (6), 703

(29) Nie, T.; Zhao, Y.; Xie, Z.; Wu, C. Macromolecules 2003, 36, 8825.

(30) Allen, C.; Han, J.; Yu, Y.; Maysinger, D.; Eisenberg, A. J. Controlled Release 2000, 63, 275.

(31) Park, S. J.; Kim, K. S.; Kim, S. H. Colloid Surf., B 2005, 43, 238.

(32) Gan, Z.; Jiang, B.; Zhang, J. J. Appl. Polym. Sci. 1996, 59.

(33) Cammas, S.; Kataoka, K. Macromol. Chem. Phys. 1995, 196, 1899.

(34) Wu, C.; Xia, K. Q. Rev. Sci. Instrum. 1994, 65 (3), 587.

(35) Chu, B. Laser Light Scattering, 2nd ed.; Academic Press: NewYork, 1991 .

(36) Kii, A.; Xu, J.; Gong, J. P.; Osada, Y.; Zhang, X. M. J. Phys. Chem. B 2001, 105, 4565.

(37) Zhang, X. M.; Xu, J.; Okawa, K.; Katsuyama, Y.; Gong, J. P.; Osada, Y.; Chen, K. S. J. Phys. Chem. B 1999, 103, 2888. 